\title{
A MODERNIDADE ENQUANTO SISTEMA POLÍTICO DO OCIDENTE, PERSPECTIVAS DOS AGENTES HEGEMÔNICOS DO PODER COLONIAL
}

Mateus Felipe Fuchs ${ }^{1}$

\begin{abstract}
RESUMO: Marx (1852) cita Hegel afirmando que todos os fatos de grande importância na "história" do mundo ocorrem duas vezes, acrescentando que Hegel esqueceu de dizer que na primeira vez como tragédia e na segunda como farsa, algo que tem me chamado atenção nas novas dinâmicas do mundo, as novas falas "inovadoras", me lembra a revisão sobre colonialismo feita pelo pensador Chatterjee, muito lido dentro da antropologia da política e temido, em meu ver, pelas escolas mais conservadoras. Chatterjee (2004) partindo de recortes político-sociais da índia enquanto colônia, e "pós-colonia", realizando uma leitura de mundo que traz aspectos curiosos, pouco explorados nas escolas latino-americanas, onde o suposto fim do imperial europeu não foi uma ressaca do poder colonial, mas sim, um encerramento estratégico que tem usa formação enquanto hegemonia na própria modernidade formulada por ele.
\end{abstract}

Palavras-chave: Modernidade; Colonialismo; Imperialismo;

\section{LA MODERNIDADE COMO SISTEMA POLÍTICO EN OCCIDENTE, PERSPECTIVAS DE LOS AGENTES HEGEMÓNICOS DEL PODER COLONIAL}

RESUMEN: Marx (1852) cita a hegel afirmando que todos los hechos de gran importancia en la "historia" del mundo ocurren dos veces, y agrega que hegel olvidó decir eso la primera vez como una tragedia y la segunda como una farsa. algo que me ha llamado la atención en las nuevas dinámicas del mundo, las nuevas líneas "innovadoras", me recuerda la revisión del colonialismo realizada por el pensador chatterjee, ampliamente leído dentro de la antropología de la política y temido, en mi opinión, por las escuelas más conservadoras. chatterjee (2004) a partir de los aspectos políticos y sociales de la india como una colonia, y "pos-colonia", realizando una lectura mundial que trae aspectos curiosos, poco explorados en las escuelas latinoamericanas, donde el supuesto fin del imperial europeo no fue una resaca del poder colonial, sino más bien, un cierre estratégico que tiene su formación como hegemonía en la misma modernidad formulada por él.

Palabras-clave: Modernidad; Colonialismo; Imperialismo;

\section{INTRODUÇÃO}

\footnotetext{
${ }^{1}$ Graduando em Antropologia com ênfase em Diversidade Cultural Latino-Americana, pela Universidade Federal da Integração Latino-Americana (UNILA). E-mail: fuchsmateus@ hotmail.com 
O poder colonial tem sempre seu poder moral fortalecido, hora pela religião que estabelece a norma, mais trade pelas teorias biológicas. Durante as expansões europeias, a questão racial, por teorias socioeconômicas de desenvolvimento, mas que sempre estabelece normais pelas quais a humanidade deve ser reconhecida, sempre fortalecendo seu poder moral. Uma das ideias centrais sobre colonialismo (CHATTERJJE, 2004) relaciona como essas expansões e posteriormente "independências" dos colonizados não era uma ressaca do poder europeu, mas um poder colonial que estava em fase de transição na disseminação do capitalismo, do progresso tecnológico e da governança moderna no lugar das expansões imperiais tradicionais.

As ideias de populações emergem como uma ideia descritiva, substitutiva na moderna arte de governar no lugar das representações da soberania dos cidadãos, onde Passa a ter um gerenciamento das populações. (CHATTERJEE, 2004) Algumas populações passam a ser referencias por meio do poder colonial de época, gerando assim no mundo moderno a constituição de hegemonias, onde as vontades modernas passam a ser produzidas para sempre escolher essas referências hegemônicas. O que busco apresentar a partir dessas ideias, é que esse fato transforma completamente a forma de governar o mundo, ou seja, a soberania pode ser rejeitada, mas a superioridade da Europa não seria questionada na modernidade. (CHATTERJEE, 2004)

Chaterjee (2004) relaciona como, em meados do século XX, o colapso dos impérios Europeus, foi decisivo para o deslocamento da dominação mundial da Europa para os Estados Unidos, uma fase de transição para o poder colonial, deslocando-se para outras formas de dominação. Para as pessoas do sul da Ásia, o conceito Europa é circunscrito pelo conceito Ocidente, onde os Estados Unidos são foco dominante. O conceito de Ocidente se construiu nas mentes da pos-colonia durante os últimos quinhentos anos (CHATTERJEE, 2004)

Os colapsos dos regimes socialistas na Europa Oriental e na União Soviética não significam o triunfo da ordem capitalista liberal que conhecemos, mas sim como um sinal de crise no projeto da modernidade inaugurado na europa no século XVIII, assim como as insuficiências e paradigmas do projeto neoliberal na década de 80. (CHATTERJEE, 2004) Nesse ponto acredito que esses colapsos que tanto construíram nossa globalização na pós-colonia representam algo proposital das estratégias do poder colonial. Seria muita 
coincidência o epicentro da Antiga União soviética no norte da Ásia, com novas alianças e formas de governabilidade estejam ocupando o cargo de potência mundial por meio das novas dinâmicas do mundo nos pós globalização. De maneira simples, o colapso dos impérios europeus significou o deslocamento de poder mundial aos Estados Unidos como representantes da categoria Ocidente. O colapso da União Soviética deslocou uma nova ordem de mundo na globalização, poderes multilocais, que tem como referência o imperial ocidental que se desloca constantemente entre potencias mundiais, onde o enfraquecimento de determinado estado nação não significa o encerramento de tal poder.

O que poderia nos direcionar para pensar que os conflitos entre as alianças de Rússia e china contra Europa e estados Unidos em uma guerra comercial informacional seria o deslocamento do poder colonial para O Norte da azia não fazem sentido se pensados em um mundo mundializado de poderes locais, onde a pós-colônia ainda é o local onde o poder colonial retira seus recursos por meio das dependências. O que precisamos notar na pós-colonia, é que não necessariamente estamos tendo uma independência do Ocidente em disputa ao Oriente, mas sim, uma nova ordem Ocidental para com as pós colônias, pois os fatos históricos não são ocasionais, e como afirma Marx, se na primeira vez como tragédia, a segunda como farsa, não se admirem de notar que os discursos políticos da China e Rússia e os novos discursos dos Estados Unidos, sejam facilmente reconhecidos e identificados nos mesmos discursos que levaram a quinhentos anos de exploração, dominação e dependência, e novos anos de mais dependência. Não se admirem se os discursos nacionalistas se repetirem.

Mas afinal, possa parecer que nada tem haver a América Latina com o outro lado do mundo, por isso, vamos discutir melhor essa questão. Chatterjee(2004) quando questiona a "independência" da Índia não busca minimizar a importância dos processos de resistência, mas como o governo britânico, o último a utilizar a dominação europeia clássica na Índia ajudou a formar as classes que muito mobilizaram os processos de resistência, e questionou por que a Europa que tanto mobilizou o poder militar nas Américas e África, atrasando suas "independências" não mobilizou o poder militar na Índia. $\mathrm{O}$ autor conclui que foi estratégico para encerrar os processos de deslocamento do poder colonial por meio do capitalismo moderno. Mas meus caros, vamos pensar essa questão desse poder militar concentrado nas Américas do sul e África. Embora não tenha 
a teoria necessária para fazer uma revisão histórica dos processos socio-politicos desses lugares, quando lembramos que o mercado escravo e a escravidão só se encerraram apenas para dar início ao novo sistema capitalista e suas novas formas de racialização e dominação, e como a abundância de recursos e especiarias nas américas e África, assim como a rentabilidade do mercado negreiro foram fundamentais para construção hegemônica do Ocidente (Europa e Estados Unidos). Os processos de independência nesses lugares não estariam tão distantes do que Chatterjee relaciona com a índia, eles foram atrasados propositalmente, para encerrar uma dependência que se mante-se presente na modernidade sustentando o poder colonial do ocidente. Com isso não minimizo a importância de nossas resistências, mas acuso a concentração do poder colonial como a forma mais desumanizadora de dominação, onde nem mesmo nossos diversos hibridismos culturais conseguiram eliminar completamente suas forças.

Elementos da presença europeia no sul da Ásia são questionados por Chatterjjee (2004), colocando em suspeita como a concentração de um poder militar que foi sempre fundamental e necessária no colonialismo europeu na Índia não foi mobilizada quando se iniciam os processos de resistência por poderes locais na índia. Esse ponto marca profundamente as concepções de hegemonia, onde por meio de exemplos históricos o autor constrói como isso representa uma enunciação referencial da Europa no mundo moderno, e consequentemente sua constituição hegemônica.

\section{O SUL GLOBAL E A NOVA ERA}

Canclini (1997) aponta como as transformações culturais por meio das novas tecnologias implicaram na construção de noções mais elaboradas de tais transformações. Por meio da urbanização, o autor demonstra que, embora esses tenham impactado o processo de hibridização cultural, os meios urbano e rural coincidem, se entrelaçando e produzindo os grupos culturais. Se para o autor o sentido urbano se restitui, deixando de ser um sistema de difusão para tornar-se uma expressão amplificada de poderes locais, complementando os fragmentos, o poder colonial que se compõe no mundo por meio e nos estados nações não poderiam ser diferente. Se observamos o decorrer das últimas décadas, a ideologia da urbanização se tornou comum na agenda das nações, em um 
sentido mais abrangente, grupos nacionais dispersos que buscam uma complementação fragmentada para uma construção dispersa.

Um período onde as cidades são vigiadas por agentes que calculam minunciosamente de forma técnica suas decisões em paralelo ao atendimento as demandas segundo critérios de rentabilidade e eficiência. $\mathrm{O}$ mercado passa a reorganizar o mundo, onde as coisas passam a ser programadas, seguindo roteiros políticos que atendam as dinâmicas do próprio mercado. (CANCLINI, 1997) Assim o mercado passa ser um elemento de disputa, e consequentemente de conflito. As novas dinâmicas de mercado, conceitualmente "o mercado" o novo eixo de transição imperial assume sua dinâmica de maneira totalizante, dispersa em poderes locais que sustentam um poder central, que se alimenta das disputas comerciais das grandes potencias, algo não mais identificável nos grupos nacionais.

Em relação as perspectivas e dinâmicas de mercado, ao apresentar transformações da economia mundial, Arrighi (1996) relaciona tais processos as ideias de hegemonia definidas pelo autor. Com a transformação de hegemonia, dentro da modernidade, o que importa é a competição para acumulação, mesmo que para isso seja necessário subalternizar outros países, dentro da ideia da competição, o ganho de um deve significar necessariamente a destruição do outro. Assim, precisa-se hegemonizar o maior número de países possíveis, buscando a acumulação capital. As mudanças de império mudaram de posição após a segunda guerra mundial, com os impactos da guerra fria, que se transformaram e ainda são experimentados atualmente, podemos posicionarmos em uma segunda fase da guerra Fria, a globalização e a pós globalização, com a questão das hegemonias, dentro de uma guerra comercial e informacional, geraram guerras informacionais ou hibridas, dentro de um caos manipulado e sistêmico, convencional a interesses hegemônicos coloniais.

Relações políticas podem articular meios de resistência a esse projeto, assim, para Arrighi (1996) o predomínio da crise estimula a reestruturação e reorganização, que são manipuladas a interesses políticos do que se construiu como referencial. As hegemonias não precisam necessariamente construir o caos, embora o façam muitas vezes por meio do sistema informacional, onde na pós colônia os impactos coloniais são vivenciados de forma intencional, fazendo com que esses países estejam sempre a beira do caos pelos 
diversos problemas resultantes de processos históricos-sociais anteriores, assim, quando conveniente o que precisa-se é estimular as dependências coloniais enfrentados por esses países, gerando crise e caos quando conveniente, mas mantendo esses países na dependência controlada, onde a construção de consentimento pontuada por David Harvey(2005) é utilizada para que se tenha a exploração constante e controle dos mesmos, e ao meu ver, uma construção produzida desde os quinhentos anos de exploração colonial. A modernidade e o neoliberalismo vendem uma falsa ideia de autonomia onde a autonomia já está estruturalmente e historicamente corrompida e é produzida dessa forma. (BUTLER, 2018).

Arrighi (1996ao pontuar que as transformações de hegemonia se dão via Caos, acredito que esse caos não precisa ser necessariamente momentâneo (o mais radical), mas ele pode ser cotidiano, onde articule as hegemonias dentro de processos que já estão produzindo consentimento, e quando conveniente ou necessário aumenta-se ou radicaliza-se o processo caos em determinados lugares de interesse ou pontos políticos. Para Arrighi (1996) o Caos sistêmico compreende que, o aumento do caos estimula o aumento da demanda de "ordem" (controle), uma nova ordem hegemônica que representa uma liderança intelectual e moral, uma liderança normativa, que estabelece domínio, essa mesma ideologia pode ser facilmente notada nas "justificativas" da Europa em suas estratégias morais de colonização. Assim a Hegemonia passa os limites Estatais transformando o mundo globalizado, e passa a compreender uma territorialidade em rede de poder do sistema-mundo formando hegemonias mundiais representadas por Estados e corporações, ocupando diversas escalas de articulação de poder, que buscam e formam verdadeiros ciclos sistêmicos de acumulação capital por meio do mercado e a guerra comercial.

Byung-chul Han (2012) apresenta questões relacionadas ao esvaziamento de significados no mundo informacional tecnológico, e como tornamo-nos ou caminhamos a uma sociedade da transparência. Uma reflexão das ideias do autor, nos permitem navegar pelo mundo das redes sociais, onde a informação pode ser facilmente manipulada e ter seu significado esvaziado. Embora os meios de comunicação façam tal feito por audiência, a diferença das redes sociais e do mundo tecnológico atual, de uma forma geral, percorre o elemento "velocidade" e "alcance". As redes sociais passam a mobilizar coisas 
mais rápido que qualquer outro meio, representando assim uma escala de alcance mundial, e a tecnologia passa a investir em tal sistema. As informações passam a ser tantas que não conseguimos mais diferenciar as informações manipuladas e transparentes (Fake News) de outros tipos de informações. Dentro da modernidade a desinformação passa a ser tanta que começam a surgir formulas para o Caos. A modernidade passa a produzir revoluções tecnológicas, onde o fetiche pela tecnologia se transforma em um modo de vida, uma "exigência" social, onde os indivíduos possam produzir o tempo inteiro, dentro de um sistema da dependência.

Para Giovanni Arrighi (1996) ocorreu uma transformação da sociedade e economia a partir da hegemonia. Ou seja, o conceito adotado por ele de "Hegemonia Mundial", refere-se a ideia de um Estado exercer funções de liderança e governo sobre um sistema de nações soberanas. Entretanto o autor pontua como sempre ocorrem mudanças e transformações que alteram o modo de funcionamento do sistema, dessa forma a mudança de hegemonia passa não ser uma ideia de "dominação" e guerra convencional, mas sim, em um sentido mais amplo, uma competição pelo poder, que implica na destruição do maior número de países possíveis, pois nessa lógica, o ganho de um deve necessariamente significar a destruição do outro, por meio de modelos mais sofisticados e não convencionais. Assim o que pode parecer não mais uma dominação imperial, pois apenas estabelece redes de poder multilocais, e a disputa direta acaba por ocorrer no território de interesse, as pós-colonias, gerando assim, um caos que não alcance os países colonialistas. A liderança de dominação moderna passa a ser a chave para a supremacia global, dessa forma, busca-se hegemonizar o maior número de países possíveis, mesmo que isso cause a destruição desses.

Caminhamos para as questões de territorialismo e capitalismo, onde a acumulação do capital representa uma expansão territorial para os governos territorialistas, onde as alianças políticas permitem o sistema de acumulação. Outro aspecto importante é a alienação ideológica aos padrões de vida e produção, que muitas vezes normatizam a vida dentro do Estado Nacional, padrões esses estabelecidos pelos poderes hegemônicos dominantes, mas não funcionam necessariamente como regra dentro do estado nacional, mas são poderes que possibilitam uma visibilidade internacional, muitas vezes dizendo como o Estado Nacional deve se comportar, mesmo que seja contrário as demandas da 
opinião pública dentro do próprio estado, entretanto tal imposição não implica necessariamente que o Estado Nacional não atenda essas demandas. Arrighi (1996) aponta que a divisão do trabalho possibilitou processos de territórios competitivos, como vamos lidar com essa competitividade? Obviamente as respostas não estarão prontas, mas por meio dos conceitos trabalhados pelo autor, podemos pensar como essas guerras não convencionais pela disputa de territórios ocorre, em âmbitos nacionais e internacionais.

\section{CONCLUSÃO}

Segundo Raffestin (1993), citando Ratzel para refletir sobre a geografia política clássica, tudo se desenvolve como se o Estado fosse o único núcleo de poder, e como se todo o poder estivesse concentrado nele, levando em consideração na geografia política clássica apenas o "Estado" e os "Grupos de Estado", sendo assim, uma geografia de Estado. Contudo o autor salienta que existem múltiplos poderes que se manifestam nas estratégias regionais e locais.

Não é novidade os interesses políticos por trás da construção da ciência enquanto ciência, um histórico da geografia política nos permite entender como essa, surge para dar sustentação ao Estado Europeu relacionado ao imperialismo e uma constante disputa imperial. Dessa forma, essa "ciência de Estado" pode ser usada para um poder heterônomo do Estado Nacional em uma lógica de dominação imperial.

A crítica de Raffestin (1993) é que o Estado não é o único produtor de poder. Para o autor, os conceitos como "Escala" remetem a articulações de poder, realizando uma reflexão da palavra "Poder" com p maiúsculo. Essas articulações de poder, quando definidas (no sentido de normatização) por uma "ciência de Estado", remetem a uma forma de dominação e hierarquização de tudo o que não está sendo definido como Estado, pois ele deve ser o único poder ou articulador desse. Dessa forma os poderes que se articulam de forma diferente ou diferenciada da lógica construída e generalizada do Estado Nacional, ocupam o campo das diferenças.

Raffestin (1993) apresenta a categoria Razteliana de "espaço vital", onde nessa ideologia, todo o Estado possuiria seu espaço vital, e aquele que não ocupa estaria fadado a desparecer, onde a perda de território representa o início do fim de um Estado. Entretanto o Estado quando desvinculado da diversidade construída pelas diferenças 
passa a se fechar em um processo de uniformidade objetiva que nega a diversidade, pois na diversidade também existe poder. Nessas perspectivas, as diferenças passam a ocupar um "território maior" do que o que se compreende por "Estado", não somente como processos alternativos de poder, mas processos alternativos de poder que passam a construir e dinamizar o próprio Estado, onde o "Estado" trabalhado por Ratzel, estado este, Europeu e imperialista da lógica de dominação passa a temer as diferenças que constituem poder, pois essas trabalham com um dinamismo de Estado que transcendem as ideias de Estado Europeu Homogêneo.

Ao dizer isso, não estamos falando que o Estado é dinamizado unicamente pelas diferenças, pois não pode-se negar sua herança de constituição de Estado enquanto Estado em relação a sua imagem que tenta espelhar-se na ideia de "Estado" imperialista no que diz respeito a hierarquização das diferenças, onde a escala se torna uma estratégia para se lidar com o poder, mas sim, pontuamos com as reflexões de Raffestin (1993), que as diferenças passam a ocupar e constituir o Estado, pois esse não é uniforme e homogêneo. Diferenças hierarquizadas pelo poder, mas constituintes desse.

Dessa forma, a frase citada na pergunta, remete as ideias de "Estado", espelhado na lógica de dominação imperialista, que só quer ver a face de sua constituição enquanto tal, inspirada em modelos acabados coloniais, ideologicamente construídos pela geopolítica, que teme outras formas de poder, medo de como Ratzel pontua, perder território (nessa ideia território remete a poder) e o Estado desparecer.

Entretanto no texto nos deparamos com a seguinte frase: "O Estado existe quando uma população instalada no território exerce a própria soberania", sem minimizar as importâncias e contribuições de Raffestin (1993), que criticam as ideias de Estado de Ratzel, nos deparamos com as seguintes questões; O Estado existe quando uma população instalada no território exerce a própria soberania, ou a própria soberania existe quando o Estado passa a definir o que é a própria soberania? Seria o Estado o modo pelo qual a população exerce soberania do território? Qual população? Que tipo de soberania? Quais seriam as formas pelas quais o Estado normatiza as diferenças para inviabilizar que essas diferenças construam o próprio Estado; nessa perspectiva, as teorias Ratzelianas se mostram eficazes para com O Estado que busca a Uniformidade, pois só vão mostrar uma face das coisas. Tampouco acho possível que respondemos aqui tais questões. 
Portanto, uma das contribuições fundamentais da crítica de Raffestin (1993), é que não podemos desvincular a ciência de interesses políticos que muitas vezes são interesses de "Estado", fato evidenciado claramente nas ideias de Ratzel, e também não podemos pensar que o Estado não possa utilizar das ciências para articular seu poder. A diversidade, construída pelas diferenças, não é apenas temida pelo Estado que funda suas bases, em partes, pela ciência e ideologia, mas é temida pelos interesses políticos de Estado que fundam o Estado enquanto Estado articulador de poder, onde ocupar uma dessas bases é dinamizar por meio da ciência e política a compreensão do próprio Estado, que passa a regulamentar e normatizar quem ocupa as instituições que fundam as próprias bases.

\section{REFERENCIAS BIBLIOGRÁFICAS}

Byung-Chul Han. Sociedade da Transparência. Editora Vozes Limitada, 31 de jul. de 2017 - 120 páginas

CANCLINI, Néstor García. Culturas Híbridas - estratégias para entrar e sair da modernidade. Tradução de Ana Regina Lessa e Heloísa Pezza Cintrão. São Paulo: EDUSP, 1997. p.283-350: Culturas híbridas, poderes oblíquos.

CHATTERJEE, Partha. Colonialismo, modernidade e política. 2004.SciELOEDUFBA.

ARRIGHI, Giovanni. O longo século XX. Hegemonia, capitalismo e territorialismo as origens do moderno sistema estatal. 1994. São Paulo: Contraponto/Unesp.

Marx, Karl. O 18 brumário e cartas a Kugelmann. 1997. 7. ed. Paz e Terra.

RAFESTIN, Claude. Por uma geografia do poder. Crítica da Geografia Política clássica. 1993. São Paulo: Ática. 